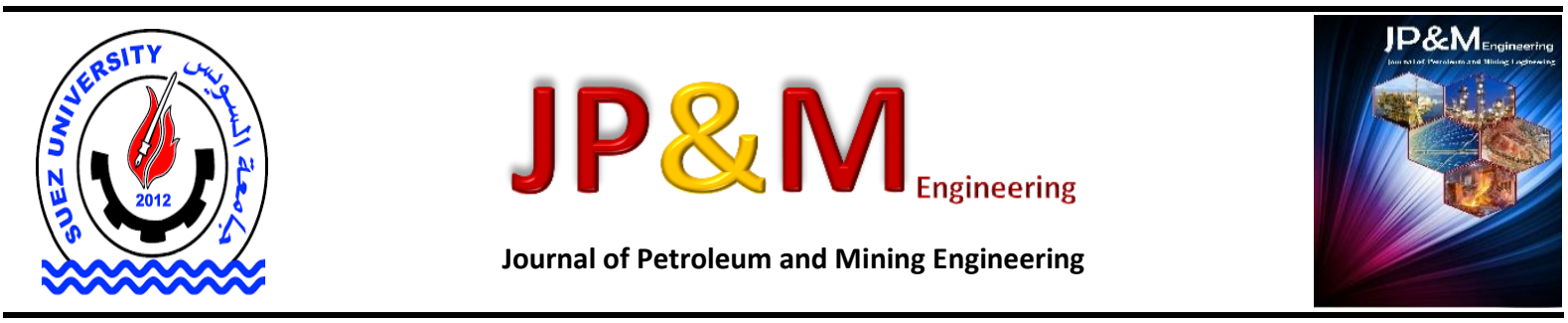

\title{
Electrical and Thermal Conductivity Performance of epoxy/SiC Composite Prepared by a Modified Apparatus
}

\author{
Nassar, A.*a , Salem, M. ${ }^{\text {b }}$, El-Batanony, I. ${ }^{\text {b }}$ and Nassar, E. ${ }^{\text {a }}$ \\ a.Mechanical Engineering Department, Higher Technological Institute, 10th of Ramadan City, Egypt \\ b. Mechanical Engineering Department, Faculty of Engineering, Al-Azhar University, Cairo, Egypt \\ *Email: amal.nasser@hti.edu.eg
}

\begin{abstract}
Article Info
Received 1 Oct. 2021

Revised 5 Dec. 2021

Accepted 13 Jan. 2022
\end{abstract}

\begin{abstract}
In this study, epoxy composites are prepared by the centrifugal mixing method. The effects of Silicon Carbide ( $\mathrm{SiC}$ ) as a reinforcement material due to its weight percentage (wt. \%), $\mathrm{SiC}$ particle sizes and mixing speed on electrical and thermal conductivity are investigated both experimentally and theoretically. The perfect dispersion of ceramic particles on the surrounding of the sample edge is found to be improved significantly and increases both electrical and thermal Conductivity. Additionally, both are increased with the decrease in the particle size, SiC wt. \% and the mixing speed. It can be attributed to the particle to particle adjoining that is created between ceramic particles and epoxy and the electron transporting. Therefore, as the manufacturing of the polymer composite on large scale is more promising ascribable its acceptable cost, low weight and could prepare ease, it can be considered for the industrial heat transfer. Compared to carbonic particles, metallic and ceramic particles are more effective at enhancing the thermal conductivities of polymer nanocomposites.
\end{abstract}

\section{Introduction}

Polymer materials have been utilized as matrices to incorporate a variety of fillers for decades. Polymers have a low density, shape-accessible residence, and various advantages from their physicochemical features of macromolecular connections. Filling polymer matrices with fillers has long been regarded to be a better approach to combine the significant differences of each and, as a result, provide an advanced cucumber for specific applications in nanotechnology through PNCs.The selection of fillers must be carefully considered when relying on the ultimate or favored features of PNCs. Indeed, high thermal conductivity polymer composites have piqued interest in heat dissipation applications to control large amounts of heat generated by integrated circuits [1-17].In the electronic and nanotechnology industries, electrically conductive polymer composites offer a wide range of applications. They offer unique features that enable them to be used as a smart material for sensors, printable electronics, optoelectronics, and various other uses[18-22]. However, in balancing the composites' complete bundle of homes, obtaining hybrid conductivities is a challenging aim. However, using one or more fillers while maintaining the mechanical residences of the polymer matrix - with the growth of a variety of fillers grow - becomes more difficult. Since the beginning of polymer composites, various fillers have been used to incorporate into the polymer matrix. [23] Particles are divided into two sizes: microparticles and nanoparticles (NPS). Organic and inorganic NPs, for example, has lately been researched and can be divided into distinct categories based on their physical or chemical properties. [24].PNCs have particles with at least one dimension of less than $100 \mathrm{~nm}$, unlike conventional micro-composites, which have particles with typical dimensions on the micrometer scale. When NPS are used as fillers in polymer matrices, this phenomenon can provide an advantage, allowing for the creation of PNCs with improved performance.

$\mathrm{SiC}$ was employed to increase the wear resistance of epoxy in previous studies [25], and the current study intends to investigate the electric characteristics of epoxy/SiC composites generated using a new mixing technique. This study aimed to reduce the electric resistance of epoxy by introducing $\mathrm{SiC}$ particles of various sizes and weight percentages. In addition, the impact of mixing speed was investigated. Researchers must first understand heat transfer since it is the transfer of thermal energy from a hot to a cold body to understand thermal conductivity in materials. It can occur in a variety of circumstances: 
1. When an object's temperature differs from that of its environment;

2. When an object has a temperature that is different from everything else around it, it has a temperature gradient.

The second law of thermodynamics indicates that the entropy of an isolated system that is not in thermal equilibrium tends to increase over a year, reaching a maximum value at equilibrium. This point implies that heat transfer from a higher to a lower temperature object is always present and will continue until thermal equilibrium is reached. Conduction, convection, and radiation are the three methods through which thermal energy is transported. Each mode has its heat transmission mechanism and pace. As a result, the rate of heat transmission in a given situation is dictated by the prevalence of a particular model.

Conduction is mainly defined as transferring thermal energy via a mixture of electron diffusion and phonon vibrations in which solids are affected by this type of heat transfer mode.

Convection transfers thermal energy from a hot gas/liquid to a colder medium in a moving medium (generally due to density differences).

The transfer of heat energy by electromagnetic waves is known as radiation. The sun has been observed to transfer energy through a (near) vacuum. [26]

\section{Materials and Methods}

Table 1 shows the full details of the materials used in the investigation. The description of mixing details and apparatus techniques were explained in the previous work [25].

\section{Electrical Conductivity}

The amount of electric conductivity (EC) is calculated by measuring the resistance of samples at different contents and sizes of $\mathrm{SiC}$ and different mixing speeds. Table 2 shows the full details of each sample. Resistance values were measured according to the ASTM standard D257 by the insulation tester megger (MIT515) model (figure 1). The samples were cylinders with $13 \mathrm{~mm}$ diameter and $90 \mathrm{~mm}$ length, detailed in table 2 . The test was performed according to the following steps:

Fixing the sample for $30 \mathrm{sec}$. to stabilize the pressure.

Running the electrical current for $1 \mathrm{~min}$.

Taking the reading.

The reading is an average of three readings.

Resistivity values were calculated by the following equation (1):

$\rho=(R A c) / h$

where

$\rho$ : resistivity $(\Omega \mathrm{mm})$,

Ac: area of the electrode $(\mathrm{mm} 2)$

$\mathrm{h}$ : the average thickness of the samples $(\mathrm{mm})$.

$\mathrm{R}$ : resistance $(\Omega)$.

then, the electric conatively $(\mathrm{S} / \mathrm{m})$ is expressed as: $\sigma=1 / \rho$
Table 1. Details of the primary materials

\begin{tabular}{|c|c|c|c|}
\hline \multirow{3}{*}{$\frac{\grave{d}}{\frac{\grave{2}}{2}}$} & \multirow{3}{*}{$\begin{array}{c}\text { Kemapoxy } \\
150 \text { JM CMB } \\
\text { International, } \\
\text { Egypt }\end{array}$} & $\begin{array}{c}\text { Density } \\
\text { at room } \\
\text { temperature }\end{array}$ & $\begin{array}{c}1.15 \\
\pm 0.02 \\
\mathrm{~kg} / \mathrm{l}\end{array}$ \\
\hline & & $\begin{array}{r}\text { Compres } \\
\text { sive strength }\end{array}$ & $\begin{array}{c}500- \\
1000 \\
\mathrm{~kg} / \mathrm{cm} 2\end{array}$ \\
\hline & & $\begin{array}{l}\text { Tensile } \\
\text { strength }\end{array}$ & $\begin{array}{c}150- \\
250 \\
\mathrm{~kg} / \mathrm{cm} 2\end{array}$ \\
\hline \multirow{2}{*}{$\begin{array}{l}\frac{u}{E} \\
\frac{\pi}{\frac{0}{0}} \\
\text { U }\end{array}$} & \multirow{2}{*}{$\begin{array}{l}\text { SiC (Sigma } \\
\text { Aldrich, } \\
\text { Germany) }\end{array}$} & $\begin{array}{c}\text { Size of } \\
\text { microparticle } \\
\text { (M) }\end{array}$ & $\begin{array}{l}>25 \\
\mu \mathrm{m}\end{array}$ \\
\hline & & $\begin{array}{c}\text { Size of } \\
\text { ultrafine } \\
\text { particles (UF) }\end{array}$ & $\begin{array}{l}>90 \\
\mathrm{~nm}\end{array}$ \\
\hline
\end{tabular}
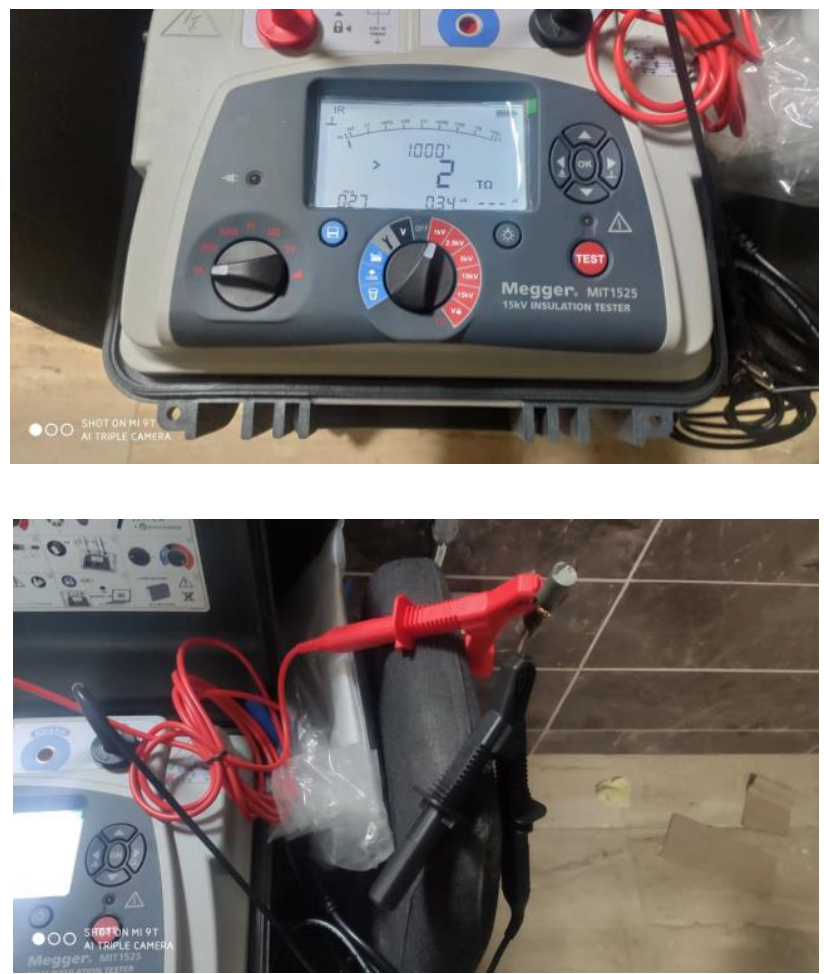

Figure 1: Measuring resistance values by insulation tester megger (MIT515) model. 
Table 2. Details of each sample

\begin{tabular}{|c|c|c|}
\hline $\begin{array}{l}\text { Sample } \\
\text { No. }\end{array}$ & $\begin{array}{l}\quad \mathrm{SiC} \\
\text { particle size, } \\
\text { (wt\%) }\end{array}$ & $\begin{array}{l}\quad \text { Mixing } \\
\text { speed } \\
(\mathrm{Hz})\end{array}$ \\
\hline 1 & UF, $10 \%$ & 10 \\
\hline 2 & UF, $10 \%$ & 20 \\
\hline 3 & UF, $10 \%$ & 30 \\
\hline 4 & UF, $20 \%$ & 10 \\
\hline 5 & UF, $20 \%$ & 20 \\
\hline 6 & UF, $20 \%$ & 30 \\
\hline 7 & UF, $30 \%$ & 10 \\
\hline 8 & UF, $30 \%$ & 20 \\
\hline 9 & UF, $30 \%$ & 30 \\
\hline 10 & $\begin{array}{l}\text { UF, } 5 \%+ \\
M, 5 \%\end{array}$ & 10 \\
\hline 11 & $\begin{array}{l}\text { UF, } 5 \%+ \\
M, 5 \%\end{array}$ & 20 \\
\hline 12 & $\begin{array}{l}\text { UF, } 5 \%+ \\
M, 5 \%\end{array}$ & 30 \\
\hline 13 & $\begin{array}{l}\text { UF,10\%+ } \\
M, 10 \%\end{array}$ & 10 \\
\hline 14 & $\begin{array}{l}\text { UF,10\%+ } \\
M, 10 \%\end{array}$ & 20 \\
\hline 15 & $\begin{array}{l}\text { UF,10\%+ } \\
M, 10 \%\end{array}$ & 30 \\
\hline 16 & $\begin{array}{l}\text { UF,15\%+ } \\
M, 15 \%\end{array}$ & 10 \\
\hline 17 & $\begin{array}{l}\text { UF,15\%+ } \\
M, 15 \%\end{array}$ & 20 \\
\hline 18 & $\begin{array}{l}\text { UF,15\%+ } \\
M, 15 \% \\
\end{array}$ & 30 \\
\hline 19 & $M, 10 \%$ & 10 \\
\hline 20 & $M, 10 \%$ & 20 \\
\hline 21 & $M, 10 \%$ & 30 \\
\hline 22 & $\mathrm{M}, 20 \%$ & 10 \\
\hline 23 & $\mathrm{M}, 20 \%$ & 20 \\
\hline 24 & $\mathrm{M}, 20 \%$ & 30 \\
\hline 25 & $\mathrm{M}, 30 \%$ & 10 \\
\hline 26 & $M, 30 \%$ & 20 \\
\hline 27 & $\mathrm{M}, 30 \%$ & 30 \\
\hline
\end{tabular}

\section{Thermal conductivity}

Some phonon modes are frequently used to ensure conduction and heat transfer in materials. $[27,28]$ The conventional Debye equation is used to predict the thermal conductivity of polymers theoretically:

$$
\lambda=(C p \times v \times 1) / 3
$$

As $\mathrm{Cp}$ denotes the capacity of heat, it refers tophonons average speed while I denotes the phonon mean free path, and $\mathrm{Cp}$ denotes specific heat capacity. Amorphous polymers have low thermal conductivity because I is often small increment with the degree of crystallinity as seen for semi-crystalline polymers; for example, when determining PTFE (polytetrafluoroethylene). [29] Metallic fillers with competent conduction capacities can be inserted into the polymer matrix, using the mechanical properties of polymers, where proper conductivity and desired electrical conductivity are required, as in metal. $[30,31]$. Nevertheless, this procedure is always followed by a decrease in the polymer's mechanical characteristics and raising the composite material's density. Ceramic filters are used when the emphasis is on thermal conductivity while preserving a reasonably high electrical resistance. Ceramics such as aluminum nitride (AIN), boron nitride (BN), and silicon carbide (SiC) have aroused interest in this respect. [32].

However, various factors, including filler packing density, particle measurement and size, surface treatment, and mixing procedure, limit the usage of this type of filler. [33-37] The volume fraction of filler is proportional to this model, given by the equation [32].

$$
\lambda c=\lambda p \times \phi p+\lambda m \times \phi m
$$

$\lambda c, \lambda p$, and $\lambda \mathrm{m}$ refer to the thermal conductivities of the composite, the filler, and the polymer matrix, respectively. $\phi \mathrm{p}$ and $\phi \mathrm{m}$ are the volume fractions of the filler and the polymer matrix, respectively. The parallel model increases the contribution of the conductive section in a percolating network and maintains complete contact among the conductive fillers. This model overestimates the thermal conductivity of the composite. It is appropriate in particular conditions, such as the direction of fibers in a continuous fiber composite. The series model in equation one determines the lower bound of effective thermal conductivity.

$$
(1 / \lambda c)=(\phi p / \lambda p)+(\phi m / \lambda m)
$$

The conductive phase's contribution is dependent on the polymer portions around the fillers, as there is no direct contact between particles or fillers. Typically, the experimental values of the composite's thermal conductivity lie between these two estimates from simple models, as shown in Fig. 2.

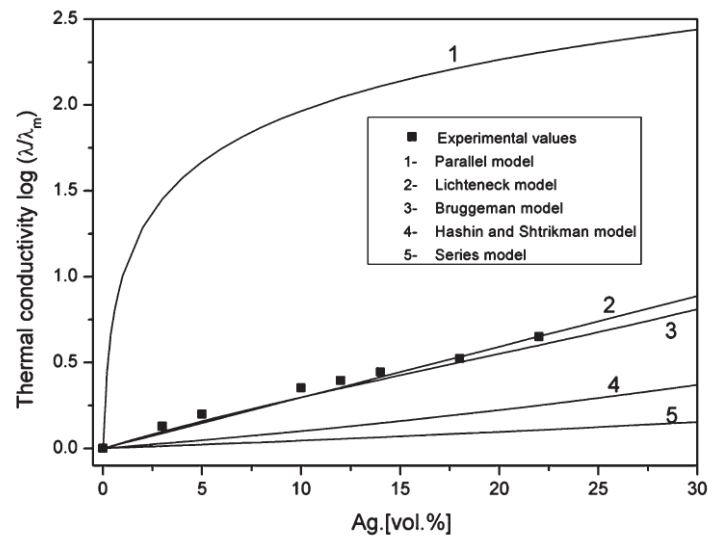

Figure 2: Experimental verifications and theoretical models [27].

Table 3 shows error \% of obtained experimental results by Che et.al [28], the values show that the error $\%$ in the mathematical models did not exceed 
$0.06 \%$. on the other hand, same results were obtained by Jouni et. Al[27], they also found that mathmatical models can calculte the thermal condactivity with high accurecy.

Table 3. Thermal properties of polymer based on a range of fillers [28]

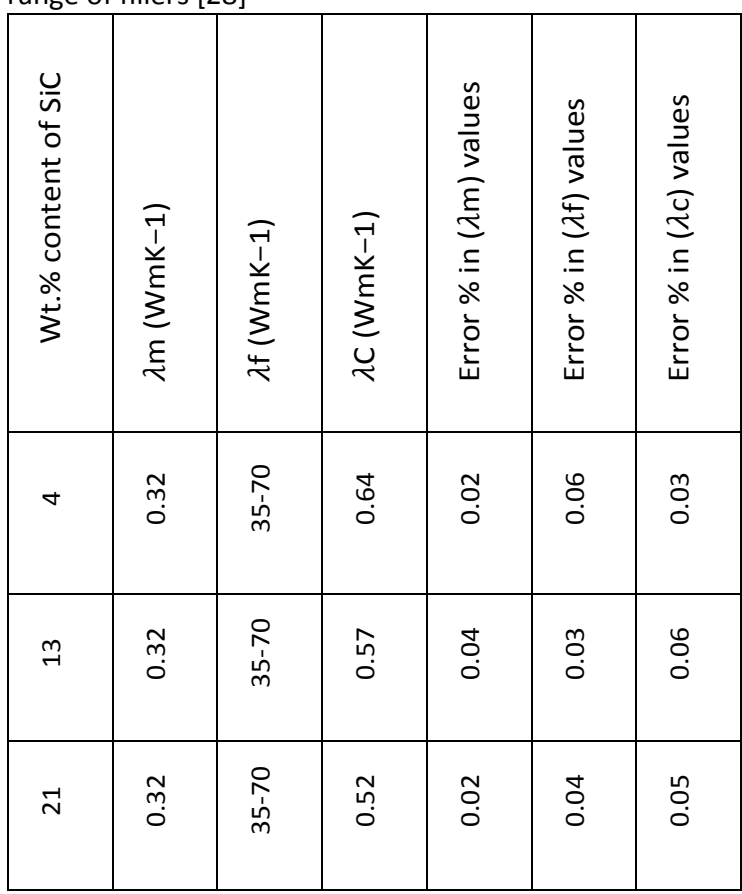

\section{Results and Discussion.}

\section{Electrical conductivity}

Polymer composites were prepared with different sizes, weights \% of SiC (wt\%), and mixing speed. To identify the changes in electric properties for each sample due to electric conductivity, values were measured. Figure (3) shows the conductivity values as a function for each sample. The figure shows that the particle size, wt\%, and mixing speed significantly affect the electrical conductivity values. Electric conductivity (EC) increases with the decrease of the SiC particle size andwt\%. On the other hand, it is decreased by the increase of the mixing.

It can be observed that by increasing the mixing speed from 10 to $30 \mathrm{HZ}$,(EC) values decrease by fixing the $\mathrm{SiC}$ particle size and $\mathrm{wt} \%$ values.

On the other hand, it can be observed that the ultra-fine SiC particle sizes show more enhancement by increasing the EC 3 times than the micro size by fixing the wt\% and mixing speed. Furthermore, it can be observed that by increasing the wt\%, the EC values decreased from 0.2 to 0.5 times with fixing the SiC particle sizes and mixing speed.

It is noted that the size of the reinforcement particles has a greater impact on the electric conductivity than the size of the matrix particles or the mixing speed. Furthermore, decreasing the size of both the reinforcement and matrix particles adds an increase in the EC. The increase of EC of composites and matrix could be attributed to the electron scattering at the SiC interface,

It appears from electric conductivity results that the particle size significantly affects the electrical conductivity values. That means the micro size samples showed lower electric conductivity than ultra-fine samples, regardless of mixing speed. This result is due to electron-transporting through $\mathrm{SiC}$ and the electron scattering at the $\mathrm{SiC}$ and epoxy interface. Also, the voids formed during the mixing process can be one of the other factors affecting the electron moving and reducing the electrical conductivity. The electron is carried through $\mathrm{SiC}$, which causes grain boundaries to expand and the matrix's microstructure to alter due to SiC inclusion [38]. The collapsed voids and their dispersion affecting with the particle sizes in the current movement across the cross-section, as shown in the previous work [25]

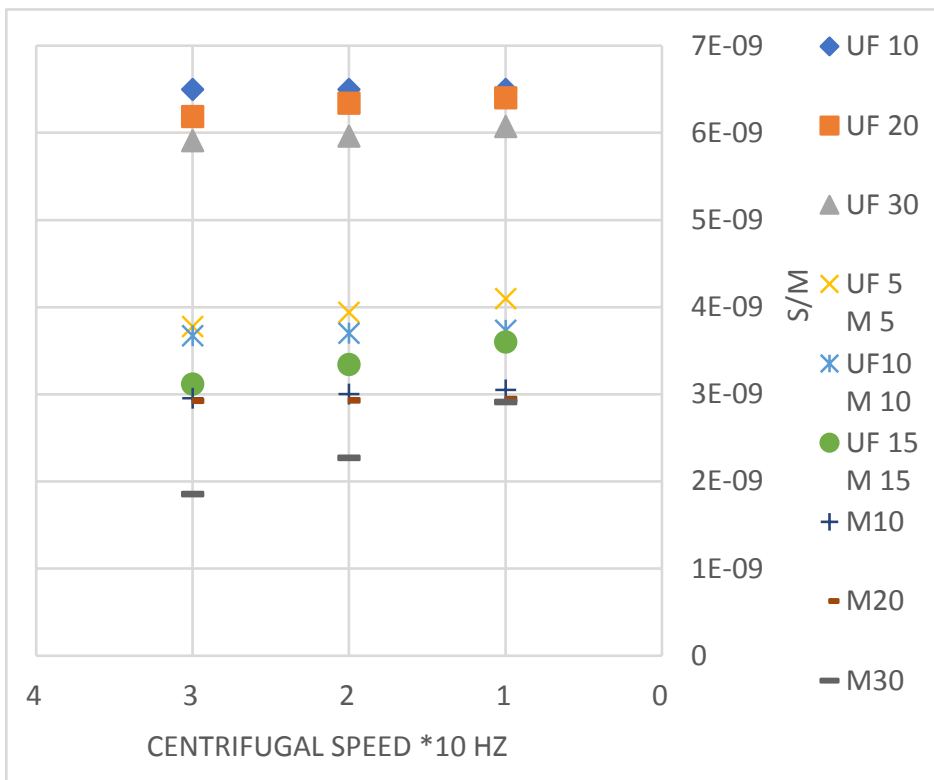

Figure 3: Conductivity values as a function for each sample.

The filler concentration determines the possibility of forming a percolating network that causes change to a conducting phase from insulating. [39] This shift occurs to ensure that conductive fillers receive the necessary attention ( $\mathrm{pc}$ ). The conductive particles are scattered at low concentrations and are less likely to come into direct touch.

The possibility of making direct connections between conductive particles grows as the filler concentration rises until it reaches critical concentration pc. The electrical conductivity of the composite increases dramatically (usually by several orders of magnitude).

Mechanisms of electronic transport in CPC Electronic conduction is represented by one of two major models, based on the insulating barriers'size, in an electrically inhomogeneous medium characterized by the coexistence of strongly conducting patches separated by insulating barriers. Charge transport between arbitrarily distributed localized electronic states is defined in these two models, which follow either a versatile range hopping (VRH) or a fluctuation-induced tunneling (FIT) mechanism. [40]

Thermally active jumps between localized electronic define the charge transfer indicates that they are randomly dispersed in energy and position 
(Fig. 4), as suggested by Mott and Davis[41]; the temperature dependence of electrical conductivity in the FIT model. Because they give strong fits to experimental data for electrical dc conductivity as a function of temperature, these two approaches have been widely employed. [42-44]

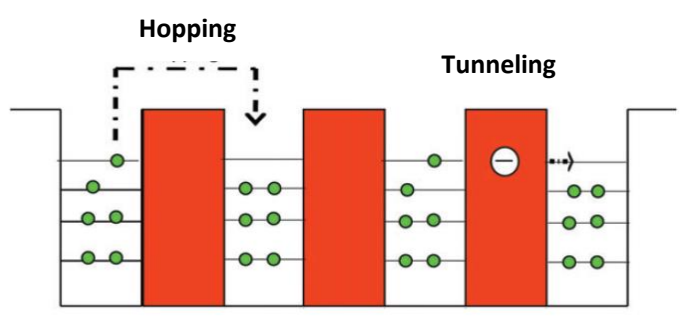

\section{Thermal conductivity}

Figure 4: Different electron transfer mechanisms[27]

The crystalline content material, as expected, has a role in improving thermal conductivity. Some information can be gleaned when comparing highdensity polyethylene (HDPE) to low-density polyethylene (LDPE).CPCs packed with metallic or ceramic particles have thermal homes. The addition of CNT fillers was not required for the manufacture of thermally performing CPCs. To achieve good thermal characteristics, further kinds of fillers, for example, metallic or metallic oxide particles, were used. Table 5 provides some examples to go along with this research. As examples of amorphous and semicrystalline matrices, it focuses on epoxy and polyethylene (PE). These composites have a much higher thermal conductivity increase than PNCs packed with CNTs. References [45-47] found epoxies with excellent thermal conductivities. In addition, the PE matrix elicits proper augmentation using micrometric fillers. The thermal conductivity increased as the particle measurement dropped for the same type of filler and matrix.

These effects reflect the composite's ability to switch heat amends when steel fillers are used. In contrast to big Ag particles, this is the case with epoxies loaded with Ag-NPs. In contrast to composites crammed with CNTs, this needs to be credited with the unique residences of particle-particle interactions and particle-matrix interfaces.

\section{Conclusions}

The consequence of mixing speed, wt.\%, and particle size of SiC particles on the electric and thermal conductivity of polymer composites are inquired. The outcomes observed that both the electrical conductivity and thermal conductivity increase with the decrement in the particle size, SiCwt \%, and the mixing speed.

Therefore, as the manufacturing of the polymer composite on a large scale is more promising ascribable its acceptable cost, low weight, and could prepare ease, it can be considered for the industrial heat transfer.
Metallic and ceramic particles outperform carbonic particles in enhancing the thermal conductivities of polymer nanocomposites. This is most likely owing to enhanced particle-particle contact and particle-matrix interaction, which increases the heat transmission capacity of the polymer composite. Furthermore, the thermal conductivity appears to change more when the particle size is reduced for the identical particle scenario.

\section{Funding sources}

This research received no external funding.

\section{Conflicts of interest}

There are no conflicts to declare

\section{References}

[1] M. Nabilah, A.; Bakar, A.; Husaini, T.; Herianto, E.; Irwan, M.; Firdaus, "Fabrication of multifiller MCF/MWCNT/SG-based bipolar plates," Ceram. Int., (2019) 1-6.

[2] P. J. González-Gutiérrez, A.G.; Pech-Canul, M.A.; Chan-Rosado, G.; Sebastian, "Studies on the physical and electrochemical properties of $\mathrm{Ni}-\mathrm{P}$ coating on commercial aluminum as bipolar plate in PEMFC," Fuel, pp. 235,( 2019) 1361-1367.

[3] V. Antunes, R.A.; De Oliveira, M.C.L.; Ett, G.; Ett, "Carbon materials in composite bipolar plates for polymer electrolyte membrane fuel cells: A review of the main challenges to improve electrical performance.," J. Power Sources, pp. 196,(2011) 2945-2961.

[4] H. Zakaria, M.Y.; Sulong, A.B.; Sahari, J.; Suherman, "Effect of the addition of milled carbon fiber as a secondary filler on the electrical conductivity of graphite/epoxy composites for electrical conductive material.," Compos. Part B Eng., pp. 83, (2015) 75-80.

[5] J. Suherman, H.; Sulong, A.B.; Sahari, "Effect of the compression molding parameters on the inplane and through-plane conductivity of carbon nanotubes/graphite/epoxy nanocomposites as bipolar plate material for a polymer electrolyte membrane fuel cell.," Ceram. Int., pp. 39,( 2013) 1277-1284.

[6] L. Planes, E.; Gloaguen, F.; Flandin, "Optimizing formulations of polymer composite with high filler content: Application to bipolar plate.," Compos. Sci. Technol., pp. 110,( 2015) 17-25.

[7] A. N. Taherian, R.; Hadianfard, M.J.; Golikand, "Manufacture of a polymer-based carbon nanocomposite as bipolar plate of proton exchange membrane fuel cells.," Mater. Des., pp. 49, (2013) 242-251.

[8] R. Taherian, "Experimental and analytical model for the electrical conductivity of polymer-based 
nanocomposites," Compos. Sci. Technol., pp. 123, ( 2016) 17-31.

[9] K. Taipalus, R.; Harmia, T.; Zhang, M.Q.; Friedrich, "The electrical conductivity of carbon-fibrereinforced polypropylene/polyaniline complexblends: Experimental characterisation and modelling.," Compos. Sci. Technol., pp. 61,(2001) 801-814.

[10] C. W. Locke, A. Severino, F. La Via, M. Reyes, J. Register, and S. E. Saddow, "Chapter 2 - SiC Films and Coatings: Amorphous, Polycrystalline, and Single Crystal Forms," S. E. B. T.-S. C. B. Saddow, Ed. Oxford: Elsevier, (2012) 17-61.

[11] Rajesh L, Ahuja T and Kumar D,"Recent progress in the development of nano-structured conducting polymers/nanocomposites for sensor applications" Sens Actuators A Phys," 136, (2009) 275-286.

[12] Thostenson ET, Ren $Z$ and Chou T$W$,"Advances in the science and technology of carbon nanotubes and their composites: a review" Composites Science and Technology 61, (2001) 18991912.

[13] Feller JF, Roth S and Bourmaud A," Conductive polymer composites: Electrical, thermal, and rheological study of injected isotactic poly(propylene)/long stainless-steel fibers for electromagnetic interferences shielding" Jornal of Applied Polymar Science 100 (2006) 3280-3287.

[14] Tung TT, Feller J-F, Kim T, Kim H, Yang WS and Suh KS," Electromagnetic properties of Fe3O4functionalized graphene and its composites with a conducting polymer" Journal of Polymer Science Part A: Polymer ChemistryVolume 50, Issue 550 (2012) 927-935.

[15] Tlili R, Boudenne A, Cecen V, Ibos L, Krupa I and Candau $Y$," Thermophysical and Electrical Properties of Nanocomposites Based on EthyleneVinylacetate Copolymer (EVA) Filled with Expanded and Unexpanded Graphite" International Journal of Thermophysics 31 (2010) 936-948.

[16] Leung SN, Khan MO, Chan E, Naguib $\mathrm{HE}$, Dawson F, Adinkrah $V$ et al.," Novel Thermally Conductive Thermoplastic/Ceramic Composite Foams" Macromolecular Materials and Engineering 297 (2012) 1014-1020,.

[17] Zhou T, Wang X, Cheng P, Wang T, Xiong D and Wang $X$, " The preparation of the poly(vinyl alcohol)/graphenenanocomposites with low percolation threshold and highelectrical conductivity by using the large-area reducedgraphene oxide sheets" Express Polymer Letter , 7 (2013) 585-594 .

[18] He H, Zhu J, Tao NJ, Nagahara LA, Amlani I and Tsui R, "A Conducting Polymer Nanojunction Switch" J Am Chem Soc 123 (2001) 7730-7731.

[19] Holtz JH and Asher SA," Polymerized colloidal crystal hydrogel films as intelligent chemical sensing materials" Nature, 389 (1997) 829-832.

[20] Dirix Y, Bastiaansen C, Caseri W, and Smith P, " Oriented Pearl-Necklace Arrays of Metallic Nanoparticles in Polymers: A New Route Toward Polarization-Dependent Color Filters " 11 (1999) 223227.
[21] Heilmann A, Werner J, Schwarzenberg D, Henkel S, Grosse P and Theil W,"Microstructure and optical properties of plasmapolymer thin films with embedded silver nanoparticles" , Thin Solid Films 270 (1995) 103-108.

[22] Karttunen M, Ruuskanen P, Pitkänen V, and Albers W, "Electrically conductive metal-polymer nanocomposites for electronics applications

"J Electron Mater37 (2008) 951-954.

[23] Harris B and Bunsell AR," Impact properties of glass fiber/carbon fibre hybrid composites, "Composites 6 (1975) 197-201

[24] Peralta-Videa JR, Zhao L, Lopez-Moreno ML, de la Rosa G, Hong J, and Gardea-Torresdey JL, " Nanomaterials and the environment: a review for the biennium," J Hazard Mater 186 (2011) 1-15

[25] A. Nassar, M. Salem, I. El-Batanony, and E. Nassar, "Improving wear resistance of epoxy/SiC composite using a modified apparatus," Polym. Polym. Compos., p. 09673911211002731, Mar. 2021.

[26]Ajit Surve," The Relation Between Thermal Conductivity And Electrical Conductivity Of Assorted Materials" International Journal For Technological Research In Engineering, Volume 6, Issue 6, February2019

[27] Mohammad Jouni, David Djurado, Valérie Massardier andGisèle Boiteux," A representative and comprehensive review ofthe electrical and thermal properties ofpolymer composites with carbon nanotubeand other nanoparticle fillers", 66 (2017) 1237-1251,

[28] Chi Q, Ma T, Dong J, et al." Enhanced Thermal Conductivity and Dielectric Properties of Iron Oxide/Polyethylene Nanocomposites", Magnetic Field. Scientific Reports. (7):3072 (2017) 1-11

[29] Majumdar A, Rohsenow W., Hartnett J. and Cho Y. McGraw-Hill " Microscale transport phenomena, in Handbook of Heat Transfer," 3rd edn, ed. by, New York, 1998, pp. 81-88.

[30] Price DM and Jarratt $M$, "Thermal conductivity of PTFE and PTFE composites "Volumes 392-393 (2002) 231-236.

[31] Boudenne A, Ibos L, Fois $M$, Majesté JC and Géhin $E$, "Electrical and thermal behavior of polypropylene filled with copper particles " Composites Part A: Applied Science and Manufacturing 36 (2005) 1545-1554.

[32] Tlili R, Cecen V, Krupa I, Boudenne A, Ibos L, Candau $Y$ et al.," Mechanical and thermophysical properties of EVA copolymer filled with nickel particles" Polymer Composites (2011) 727-736.

[33] Ishida $\mathrm{H}$ and Rimdusit S, "Very high thermal conductivity obtained by boron nitride-filled polybenzoxazine " Thermochimica Acta, 320 (1998) 177-186.

[34] Ohashi M, Kawakami S, Yokogawa Y and Lai GC," Spherical Aluminum Nitride Fillers for HeatConducting Plastic Packages" Journal of the American Ceramic Society 88 (2005) 2615-2618.

[35] $\mathrm{Mu} \mathrm{Q}$, Feng $\mathrm{S}$ and Diao G," Thermal conductivity of silicone rubber filled with $\mathrm{ZnO"}$ Polymer Composites 28 (2007) 125-130. 
[36] Yu S, Hing P and Hu X,"Thermal conductivity of polystyrene-aluminum nitride composite" Composites Part A: Applied Science and Manufacturing 33 (2002) 289-292.

[37] Gu J, Zhang Q, Dang J, Zhang J, and Yang Z," Thermal conductivity and mechanical properties of aluminum nitride filled linear low-density polyethylene composites" Polymer Engineering \& Science 49 (2009) 1030-1034.

[38] Zhou W, Qi S, An Q, Zhao H and Liu $\mathrm{N}$,"Thermal conductivity of boron nitride reinforced polyethylene composites" Materials Research Bulletin 42 (2007) 1863-1873.

[39] Ataev I, Dedegkaeva L, Manukyants A, Ponezhev M, Punis V, Sozaev V, "Thermal and Electrical Conductivity of a Copper- Aluminum Micro (Nano) composite Material," Bulletin of the Russian Academy of Sciences, 79 (2015) 1380-1382.

[40] Kirkpatrick S," Percolation and Conduction" Reviews of Modern Physics45 (1973) 574-588.

[41] Sheng P, " Fluctuation-induced tunneling conduction in disordered materials " Physical Review B 21 (1980) 2180-2195. 